\title{
Performance-based plastic design method for tall hybrid coupled walls
}

\author{
Watchara Chan-Anan, ${ }^{1 *}$ Sutat Leelataviwat ${ }^{1}$ and Subhash C. Goel ${ }^{2}$ \\ ${ }^{1}$ Department of Civil Engineering, King Mongkut's University of Technology Thonburi, Bangkok, Thailand \\ ${ }^{2}$ Department of Civil and Environmental Engineering, University of Michigan, Ann Arbor, Michigan, USA
}

\begin{abstract}
SUMMARY
The research presented herein involves a performance-based design method for a tall hybrid coupled wall $(\mathrm{HCW})$ system. For this study, HCW structures were designed with a performance-based plastic design (PBPD) method. This approach directly accounts for inelastic structural behavior and considers design lateral force distribution at ultimate limit state. The design concept uses a pre-selected target drift and yield mechanism as key performance limit states. The yield mechanism consists of shear yielding in the coupling beams and flexural yielding of reinforced concrete walls at the bases. HCW structures with varying heights and coupling ratios (CRs) were designed and subjected to a series of nonlinear dynamic analyses. The results indicated that the CR strongly influences the response of the structure. The structures could also be under-designed when the inelastic distribution of lateral forces owing to higher modes was not properly considered. Finally, a design method to account for higher mode effects within the PBPD framework was presented. The method was validated using the results from nonlinear analyses. Copyright (C) 2016 John Wiley \& Sons, Ltd.
\end{abstract}

Received 21 July 2015; Revised 07 December 2015; Accepted 04 January 2016

KEY WORDS: performance-based plastic design; hybrid coupled wall; coupling ratios; shear yielding; flexural yielding; yield mechanism

\section{INTRODUCTION}

A hybrid coupled wall (HCW) system consists of two or more reinforced concrete wall piers connected together by steel coupling beams. The coupling action reduces the overturning moments of the individual walls, while the steel coupling beams dissipate seismic energy along the height of the structure through inelastic deformations. In principle, the load-carrying mechanism of an HCW is similar to that of a conventional reinforced concrete (RC) coupled wall system. However, the use of steel coupling beams prevents the shear strength degradation issues that are associated with conventional RC coupling beams and results in superior seismic performance (Harries et al., 1993). To date, extensive research has been conducted on the system behavior, analysis, and design of HCW systems (El-Tawil et al., 2010). El-Tawil et al., (2010) presented a review on the prevailing design approaches for HCW. Based on El-Tawil et al., (2010), two design methods can be adopted for an HCW system, namely, the prescriptive design method (PrDM) and the performance-based design method (PBDM). In the PrDM, the system is designed using linear elastic force-based methods, such as the equivalent lateral force analysis or modal response spectrum analysis procedures. In the PBDM, a preliminary design of the structure is first carried out. The performance of the overall structure and the key elements are verified using a nonlinear analysis procedure. Design iterations are then performed until all elements in the system meet the desired performance acceptance criteria.

*Correspondence to: Watchara Chan-Anan, Department of Civil Engineering, King Mongkut's University of Technology Thonburi, Bangkok, Thailand.

E-mail: watchara@npru.ac.th 
An efficient PBDM for HCW systems is presented herein. The method is based on a design procedure called the performance-based plastic design (PBPD) method (Goel and Chao, 2008). The PBPD approach has been successfully applied for the design of various structural systems (Lee and Goel, 2001; Chao and Goel, 2006; Chao et al., 2008; Goel et al., 2010). For this study, the PBPD method is modified to account for the unique structural characteristics found in tall coupled wall structures (Chan-Anan and Leelataviwat, 2010). Recent research results suggest that the behavior of a tall conventional isolated or coupled wall is more complicated than previously believed. This includes the non-uniform story drift distribution, higher mode effects, and shear migration from the tension wall to the compression wall (Beyer et al., 2005; Fox et al., 2014). In this study, HCW structures with varying heights and coupling ratios were designed using the PBPD method and subjected to a series of nonlinear dynamic analyses. The key response parameters, including the important aspects of the coupling action and higher mode effect, are presented and discussed.

\section{PBPD METHOD FOR HCW SYSTEMS}

The PBPD method is a performance-based design procedure that directly accounts for inelastic structural behavior and considers lateral design force distribution at the ultimate limit state (Goel and Chao, 2008). The design concept uses a pre-selected target drift and a yield mechanism as key performance limit states. The required design base shear is derived corresponding to a target drift level and a selected yield mechanism using the energy balance concept. A plastic (limit) design is then used to design the structure to achieve the selected mechanism. Because the nonlinear behavior and the deformation criteria are considered explicitly in the design process, the PBPD method ensures that the structure performs as intended in the nonlinear range. The PBPD methodology thus fulfills the goals of performance-based design and allows the designers to clearly prescribe the behavior for various hazard levels.

In previous studies of the PBPD method, the design base shear, the yield mechanism, and the target performance of a structure have all been derived based on the assumption of a uniform story drift distribution along the height of the structure. The deformation is measured in an average sense by the 'roof drift', the roof displacement divided by the total height of the system. For the moment frame system, where the shear deformation governs the response, this assumption leads to satisfactory design results. For coupled wall structures, the notion of the roof drift as the representative response parameter can be misleading because the deformation (or drift) of the wall system is inherently non-uniform. The drifts, especially in the upper stories in some stories may be significantly different from the roof drift. This is due to the nature of the wall that acts essentially as a cantilever structure. The lateral drifts are thus generally small in the lower part because of the fixity at the base and become progressively larger in the upper part. The design of this system must take this inherent variation into account. The PBPD procedure presented in this paper is modified to consider this non-uniform drift. In addition, in previous studies of the PBPD method, the effect of higher mode response is considered indirectly by adjusting the design lateral forces to follow with the response of structures in the inelastic range (Chao et al., 2007). For tall coupled walls, this adjustment alone may not be sufficient to capture the effects of higher modes. In this study, the PBPD procedure is also modified to directly quantify the higher mode effects. Key aspects of the PBPD method for HCW systems are provided in the following sections.

\subsection{Selection of a yield mechanism and a target drift}

The PBPD method begins by selecting a target yield mechanism with a set of designated yielding members (DYMs). For the HCW system, the selected mechanism consists of flexural or shear yielding of the coupling beams and flexural hinging at the bases of the walls. Figure 1. shows the selected yield mechanism and the idealized mechanism used for plastic mechanism analysis.

After defining the desirable yield mechanism, the selection of a target drift for an intended hazard level then follows. The target drift is selected to limit the system, and the element ductility demands for a given hazard level. For HCW systems, the target drift is selected mainly to limit the plastic rotations at the base of the walls $\left(\theta_{p}\right)$. 


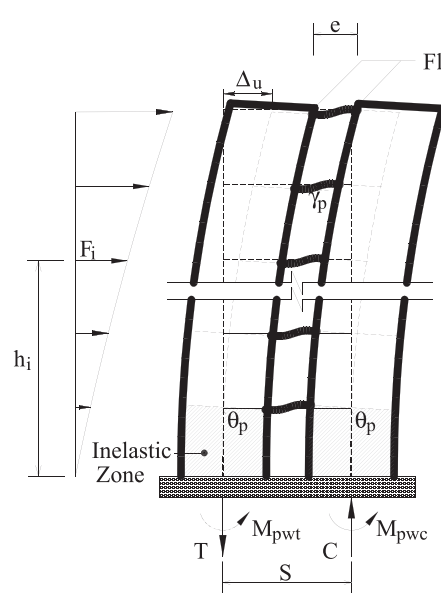

(a) Yield Mechanism

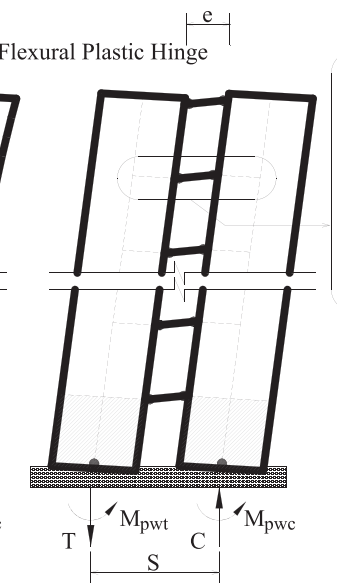

(b) Idealized Yield Mechanism

Figure 1. Yield mechanism of HCW system.

The relationship between the plastic rotation and the target story drift for the selected yield mechanism is given by (Chan-Anan and Leelataviwat, 2015)

$$
\theta_{\mathrm{p}}=\theta_{\mathrm{target}}-\theta_{\mathrm{y}}=\frac{\theta_{\max }}{\sigma_{\mathrm{d}}}-\theta_{\mathrm{y}}
$$

where $\theta_{p}$ is the plastic rotation, $\theta_{\text {target }}$ is the target story drift, $\theta_{\max }$ is the selected maximum (peak) story drift for the system under a given hazard level, $\sigma_{\mathrm{d}}$ is the ratio of the maximum inter-story drift ratio over the height of the building to the average drift ratio under first-mode lateral forces, and $\theta_{\mathrm{y}}$ is the yield drift of the system. The factor $\sigma_{\mathrm{d}}$ is used to account for the fact that the actual peak story drift may be significantly larger than the uniform, average story drift used in the plastic mechanism analysis, as shown in Figure 1.

The value of $\sigma_{\mathrm{d}}$ for a coupled wall system depends on several factors such as the degree of coupling between the walls, the variation of the coupling beam strength along the height, and the ground motion characteristics. It also varies with time, making it difficult to assess the expected value of $\sigma_{\mathrm{d}}$.

For design purpose, the value of $\sigma_{\mathrm{d}}$ for a coupled wall with low coupling ratio can be estimated by assuming that the behavior of the system is approximately similar to the behavior of an isolated wall. The vibration mode shapes of an elastic wall with fixed base having a uniform cross-section can be derived analytically. The first two normalized mode shapes are given in Figure 2. By examining the mode shapes, it can be found that the drift at the roof level is as high as 1.4 times the average drift (roof displacement divided by the total height) for the first mode and 4.7 times for the second mode. A value of 1.7 for $\sigma_{\mathrm{d}}$ is proposed and used in this study. This value is computed by taking the weighted average of $\sigma_{\mathrm{d}}$ for the first and second modes with the weights equal to $\Gamma_{\mathrm{i}} S_{\mathrm{di}}$ and with the spectral displacement assumed to be proportional to the period. $\Gamma_{\mathrm{i}}$ is the modal participation factor, and $S_{\mathrm{di}}$ is the spectral displacement of the first two modes.

It should be noted that both $\sigma_{\mathrm{d}}$ and the yield drift $\theta_{\mathrm{y}}$ may be obtained by any rational method. NEHRP (2009) provides guidelines to estimate $\sigma_{\mathrm{d}}$ and $\theta_{\mathrm{y}}$ for different structural systems and heights. Regardless of the method used to obtain the value of $\sigma_{\mathrm{d}}$ and $\theta_{\mathrm{y}}$, the value of the selected target drift or peak story drift must ensure that the plastic rotation at the base is not larger than the plastic rotation limits; otherwise, the value must be revised. Similar to $\sigma_{\mathrm{d}}$ and $\theta_{\mathrm{y}}$, plastic rotation limits may be obtained by any rational method or by using appropriate specifications (ASCE, 2005). 


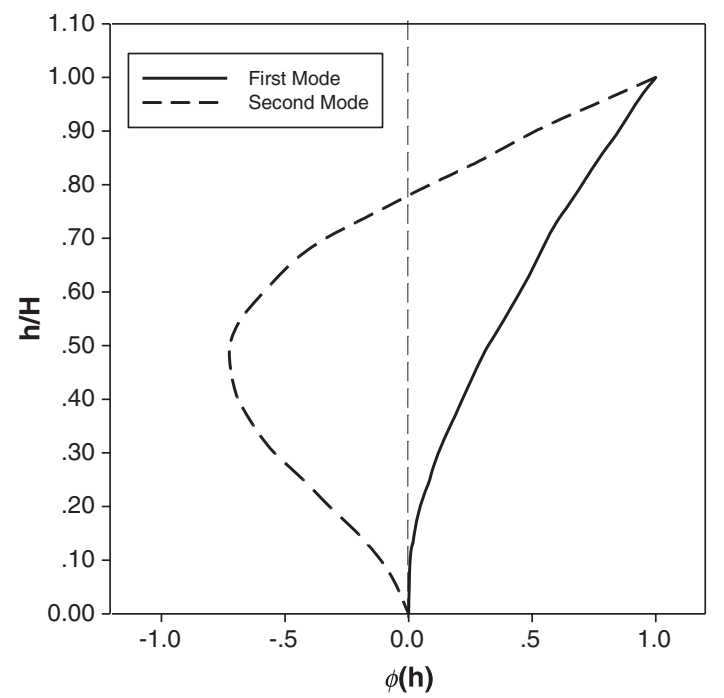

Figure 2. The normalized mode shapes of a uniform cantilever wall with fixed base.

\subsection{Design base shear}

In the PBPD method, the design base shear is computed using the modified energy balance concept (Lee and Goel, 2001; Leelataviwat et al., 2008). The concept is based on the assumption that the energies computed from the monotonic load-deformation response of the inelastic system and of the corresponding elastic system are related (Figure 3.):

$$
E_{\mathrm{e}}+E_{\mathrm{p}}=\gamma \frac{1}{2} M S_{\mathrm{v}}^{2}
$$

where $E_{\mathrm{e}}$ and $E_{\mathrm{p}}$ are respectively the elastic and plastic components of the energy needed to push the structure up to the target drift, $S_{\mathrm{v}}$ is the design pseudo-spectral velocity, $M$ is the total mass of the system, and $\gamma$ is the energy factor (Lee and Goel, 2001). The energy factor is defined as the ratio of the energy absorbed by the inelastic system to that of the equivalent elastic system and is given as

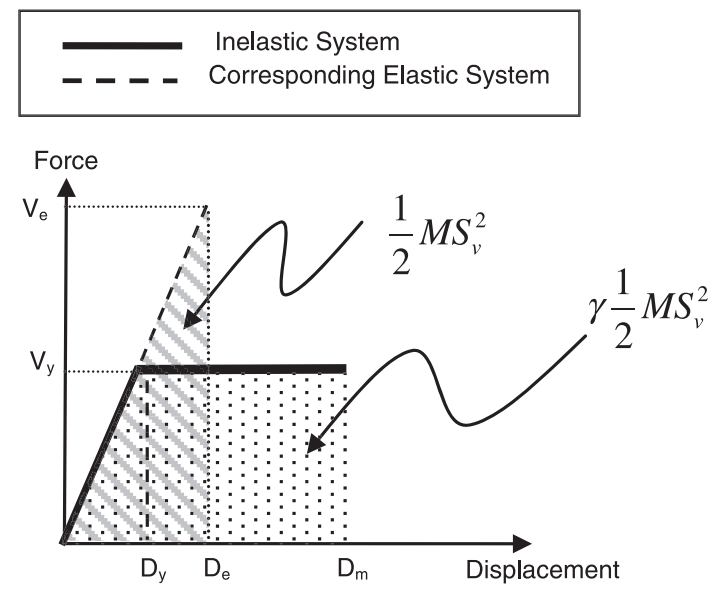

Figure 3. Modified energy balance concept (Lee and Goel, 2001). 


$$
\gamma=\frac{2 \mu-1}{R_{\mu}^{2}}
$$

where $\mu$ is the ductility ratio and $R_{\mu}$ is the yield force reduction factor. The energy factor can be computed for a given ductility level using any $R_{\mu}-\mu-T$ equation, such as the one developed by Newmark and Hall (1982). Once a target ductility level is selected and the energy factor is computed, the base shear at yield $\left(V_{\mathrm{y}}\right)$ can then be calculated as follows:

$$
\frac{V_{\mathrm{y}}}{W}=\frac{-\alpha+\sqrt{\alpha^{2}+4 \gamma C_{\mathrm{e}}^{2}}}{2}
$$

where $W$ is the weight of the structure, $C_{\mathrm{e}}$ is the normalized design pseudo-acceleration $\left(S_{\mathrm{a}} / g\right)$, and $\alpha$ is a parameter given by

$$
\alpha=\left(\sum_{i=1}^{n} \lambda_{i} h_{i}\right) \frac{\theta_{\mathrm{p}} 8 \pi^{2}}{T^{2} g}
$$

In the aforementioned equation, $T$ is the estimated period from code, $h_{i}$ is the height from the ground to the floor level $i$, and $\lambda_{\mathrm{i}}$ is the lateral force distribution factor. The lateral force at level $i, F_{\mathrm{i}}$, is assumed to be of the form

$$
F_{i}=\lambda_{i} V_{\mathrm{y}}
$$

A distribution based on a previous study (Chao et al., 2007) is used in this study and is given by

$$
\lambda_{i}=\left(\beta_{i}-\beta_{i+1}\right)\left(\frac{w_{n} h_{n}}{\sum_{j=1}^{n} w_{j} h_{j}}\right)^{0.50 T^{-0.2}}
$$

where $w_{n}$ is the weight of the structure at the top level $n, h_{n}$ is the height from the ground to the top level, and $\beta_{i}$ is the ratio of the story shear at level $i$ to that of the top story (level $n$ ).

$$
\beta_{i}=\frac{V_{i}}{V_{n}}=\left(\frac{\sum_{j=i}^{n} w_{j} h_{j}}{w_{n} h_{n}}\right)^{0.50 T^{-0.2}}
$$

In Equation (7), for $i=n, \beta_{\mathrm{n}+1}=0$.

\subsection{Plastic design of HCW systems}

In the PBPD method, a plastic mechanism analysis is used to determine the strength of the Designated Yielding Members (DYMs) based on the idealized mechanism shown in Figure 1. The relative strength of the beam at each level has to be first assigned based on a predetermined strength distribution pattern. Past studies on HCWs have suggested the use of either a constant or varying beam strength along the height (El-Tawil et al., 2010). In this study, the beam strength at each level, $M_{\mathrm{pbi}}$, is assumed to be proportional to $\beta_{\mathrm{i}}$ shown in Equation (8): 


$$
M_{\mathrm{pbi}}=\beta_{i} M_{\mathrm{pb}}=\beta_{i} e \frac{V_{\mathrm{pb}}}{2}
$$

where $M_{\mathrm{pb}}$ is the plastic moment of the coupling at the roof level in the case of flexural yielding, $V_{\mathrm{pb}}$ is the plastic shear strength of the beam at the roof level in the case of shear yielding, and $e$ is the length of the coupling beam or the spacing between the two walls. Based on the idealized mechanism shown in Figure 1, the work equation can be written in terms of $M_{\mathrm{pb}}$ or $V_{\mathrm{pb}}$. For the case where shear yielding applies

$$
\sum_{i=1}^{N} F_{i} h_{i} \theta_{\mathrm{p}}=M_{\mathrm{pw}} \theta_{\mathrm{p}}+\sum_{i=1}^{N}\left(\beta_{i} V_{\mathrm{pb}} e\right) \gamma_{\mathrm{p}}
$$

In the aforementioned equation, $M_{\mathrm{pw}}$ is the sum of the flexural strengths at the bases of the walls on the tension side $\left(M_{\mathrm{pwt}}\right)$ and the compression side $\left(M_{\mathrm{pwc}}\right), \gamma_{\mathrm{p}}$ is the plastic rotation of the beams, $N$ is the story number, $h_{\mathrm{i}}$ is the height of the floor level $i$ from the base, and $\theta_{\mathrm{p}}, F_{\mathrm{i}}, M_{\mathrm{pbi}}$, and $V_{\mathrm{pb}}$ are as defined previously. The relationship between $\theta_{\mathrm{p}}$ and $\gamma_{\mathrm{p}}$ can be found by using the kinematics of the selected yield mechanism.

To solve Equation (10), once $\theta_{\mathrm{p}}, F_{i}$, and $\beta_{i}$ are defined, a relationship between $M_{\mathrm{pw}}$ and the beam strengths along the height must be first established. This is accomplished by using a parameter called the coupling ratio (CR) (Hassan and El-Tawil, 2004, 2006; El Tawil et al., 2010), which is defined as the ratio of the moment due to the coupling effect to the total overturning moment (Figure 1):

$$
C R=\frac{C \cdot s}{M_{\mathrm{pw}}+C \cdot S}=\frac{\left(\sum_{i=1}^{N} \beta_{i} V_{\mathrm{pb}}\right) \cdot s}{M_{\mathrm{pw}}+\left(\sum_{i=1}^{N} \beta_{i} V_{\mathrm{pb}}\right) \cdot s}
$$

As CR approaches 0 , the system behaves as an isolated wall system. On the other hand, when CR approaches 1 , the system becomes fully coupled. The coupling ratio can be arbitrarily selected. However, past research indicates that the optimum coupling ratio for systems with steel coupling beams is on the order of $0.30-0.65$. These values can be used as a starting point for the PBPD of HCW systems. Once the CR is selected, Equations (10) and (11) can be solved to determine $M_{\mathrm{pw}}$ and $V_{\mathrm{pb}}$. The beam sizes and the amount of longitudinal wall reinforcement at the base can then be calculated as well.

For the walls, the total strength $M_{\mathrm{pw}}$ must be distributed between the walls on the tension and the compression sides. Research results have shown that the internal forces in the tension and compression walls can be significantly different (Beyer et al., 2005). Analyses carried out in this study indicated that this distribution also depends strongly on the CR. For low CR values, the walls behave nearly similar to isolated walls, and the walls on the tension and compression sides carry approximately equal bending moment (50-50 distribution). As the CR becomes larger, the wall on the compression side carries a significantly larger portion of the overall moment and shear force. Based on the results of some trial nonlinear dynamic analyses, the distribution can be on the order of 60-40 for a CR of 0.3 . This distribution changes progressively to approximately $70-30$ for a CR of 0.5 and $80-20$ for a $\mathrm{CR}$ of 0.75 . This distribution was later confirmed based on the results which will be presented later in this paper.

For the coupling beams, previous research indicates that steel coupling beams behave similarly to link beams in eccentrically braced rrames (Harries et al., 1993). The design can be carried out using current design specifications such as AISC (2010). Sufficient embedment length of the coupling beam into the concrete wall piers is an essential key in transferring the forces. Different models for calculating embedment lengths have been developed (Park and Yun, 2005). 


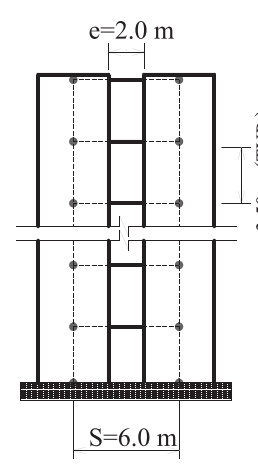

(a) Elevation

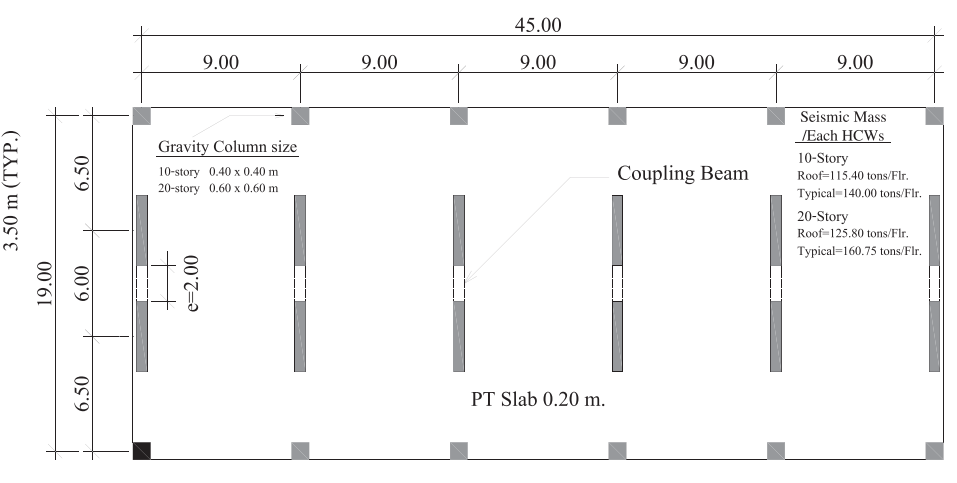

(b) Plan

Figure 4. Example structure (Chaallal and Ghlamallah, 1996).

Table 1. Summary of the PBPD parameters for the example HCW structures.

\begin{tabular}{lcccccccccc}
\hline Structure & $S_{\mathrm{a}}(\mathrm{g})$ & $\theta_{\text {target }}(\mathrm{rad})$ & $\theta_{\mathrm{y}}(\mathrm{rad})$ & $\theta_{\mathrm{p}}(\mathrm{rad})$ & $\gamma_{\mathrm{p}}(\mathrm{rad})$ & $\mu_{\mathrm{s}}$ & $R_{\mu}$ & $\gamma$ & $\alpha$ & $\frac{V}{W}$ \\
\hline 10-story & 0.66 & 0.008 & 0.004 & 0.004 & 0.012 & 2 & 2 & 0.75 & 1.10 & 0.26 \\
20-story & 0.36 & 0.008 & 0.004 & 0.004 & 0.012 & 2 & 2 & 0.75 & 0.71 & 0.12 \\
\hline
\end{tabular}

Note: $\sigma_{\mathrm{d}}$ is assumed to be 1.7 and $\theta_{\max }$ equals 0.014 for all cases.

\section{DESIGN OF NON-YIELDING ELEMENTS}

Past research results from several investigators have shown that higher modes play a significant role in the internal forces, particularly for non-yielding elements. Non-yielding members in HCW systems include the walls above the plastic hinge regions, which must be designed to remain essentially elastic and to avoid shear failure. Several proposals to consider the higher mode effects have been proposed (Fox et al., 2014), several of these methods rely on the superposition of the design forces with the forces obtained from other vibration modes. Priestley et al. (2007), based on an earlier work by Eibl and Keintzel (1988), proposed a method that can be used to obtain the envelopes of the internal forces. The method is based on the assumption that deformation ductility is primarily governed by the first mode. Effects of higher modes can be treated as elastic. The design method for a concrete wall consists of obtaining the internal forces corresponding to the development of the

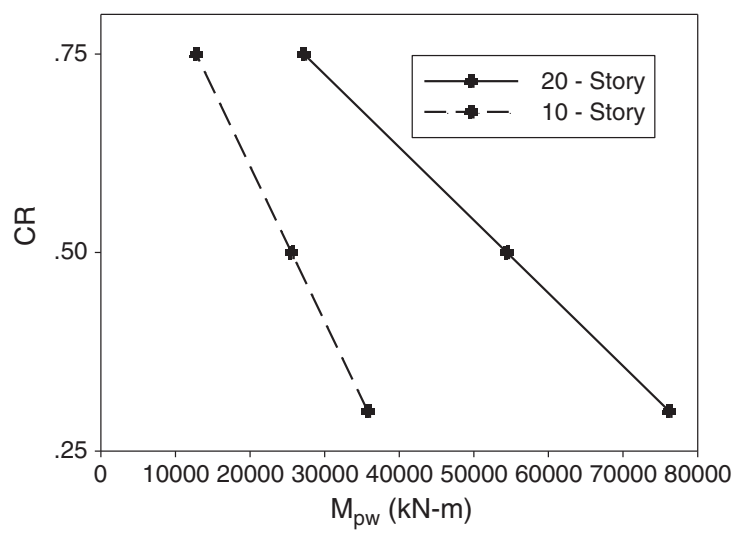

Figure 5. Required total plastic moment at the base of the structure. 
Table 2. Concrete wall dimension and reinforcement of the 10-story HCW structure example structures.

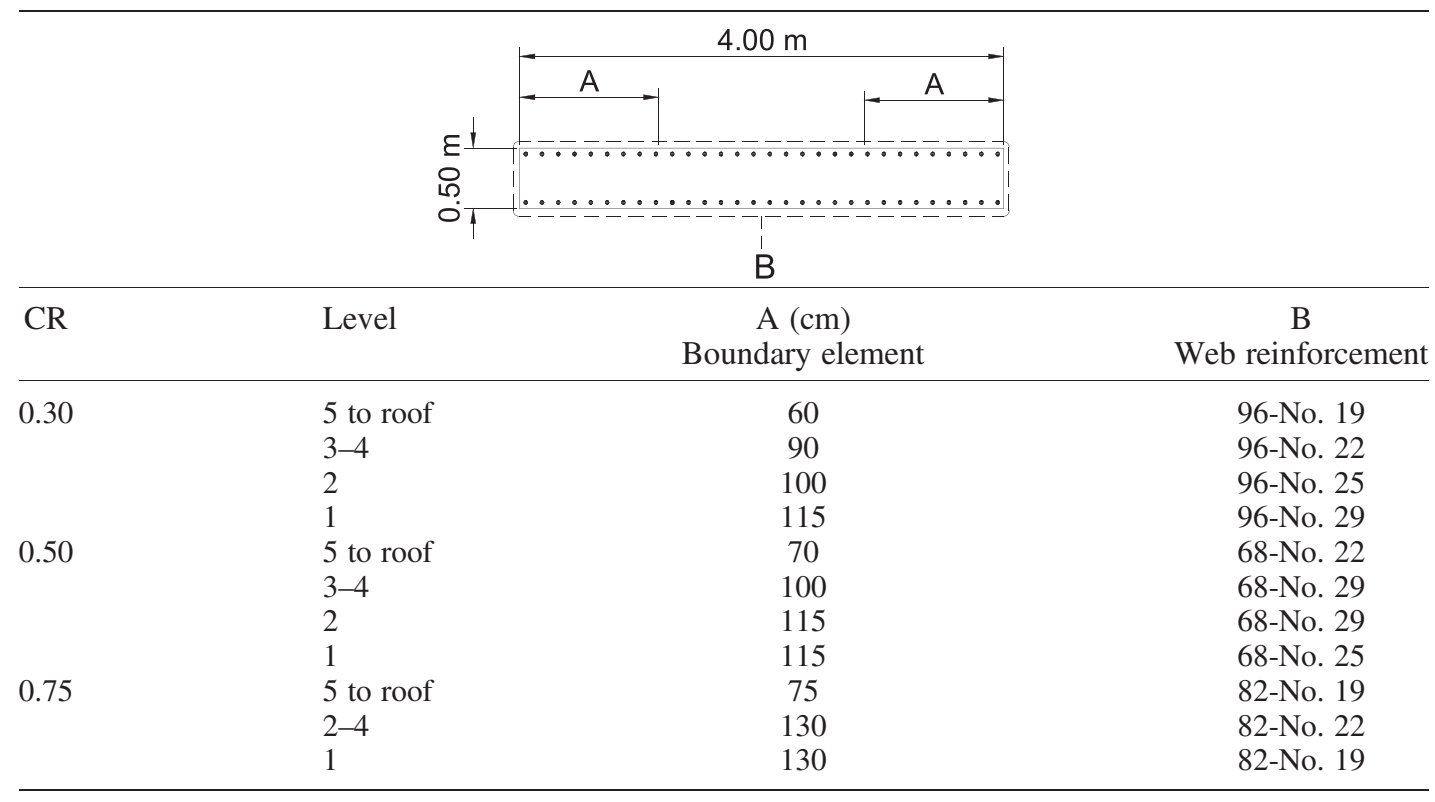

base moment capacity and adding them to the internal forces from the higher modes.

The Eurocode8 (CEN, 2004) has also adopted a similar approach for the design of shear walls.

For the PBPD method, the internal forces corresponding to the development of the base moment capacity $\left(Q_{\mathrm{y}}\right)$ can be computed based on the design base shear $V_{\mathrm{y}}$ given in Equation (4). Using only

Table 3. Concrete wall dimension and reinforcement of the 20-story HCW structure example structures.

\begin{tabular}{|c|c|c|c|c|c|}
\hline & & $=$ & $\begin{array}{l}60 \mathrm{~m} \\
\mathrm{~m}\end{array}$ & $\begin{array}{c}\mathrm{m} \\
\mathrm{C}\end{array}$ & \\
\hline CR & Level & $\begin{array}{c}\text { A }(\mathrm{cm}) \\
\text { Boundary confinement }\end{array}$ & $\begin{array}{c}\text { B }(\mathrm{cm}) \\
\text { Web thickness }\end{array}$ & $\begin{array}{c}\text { C } \\
\text { Boundary zone reinforcement }\end{array}$ & Web reinforcement \\
\hline 0.30 & $\begin{array}{c}15 \text { to roof } \\
6-14 \\
3-5 \\
1-2\end{array}$ & $\begin{array}{l}\text { Not required } \\
\text { Not required } \\
30 \\
50\end{array}$ & $\begin{array}{l}60 \\
60 \\
60 \\
60\end{array}$ & $\begin{array}{l}48 \text {-No. } 19 \\
48-N o .25 \\
48-N o .25 \\
48-N o .29\end{array}$ & $\begin{array}{l}\text { 25-No. } 19 \\
\text { 25-No. } 25 \\
\text { 25-No. } 25 \\
\text { 28-No. } 29\end{array}$ \\
\hline 0.50 & $\begin{array}{c}10 \text { to roof } \\
6-9 \\
3-5 \\
1-2\end{array}$ & $\begin{array}{l}\text { Not required } \\
25 \\
70 \\
90\end{array}$ & $\begin{array}{l}60 \\
60 \\
60 \\
60\end{array}$ & $\begin{array}{l}48-N o .22 \\
48-N o .22 \\
48-N o .29 \\
48-N o .22\end{array}$ & $\begin{array}{l}\text { 28-No. } 22 \\
28-N o .22 \\
\text { 28-No. } 29 \\
28-N o .22\end{array}$ \\
\hline 0.75 & $\begin{array}{c}15 \text { to roof } \\
10-14 \\
6-9 \\
3-5 \\
1-2\end{array}$ & $\begin{array}{c}\text { Not required } \\
\text { Not required } \\
75 \\
90 \\
130\end{array}$ & $\begin{array}{l}60 \\
60 \\
60 \\
70 \\
70\end{array}$ & $\begin{array}{l}48 \text {-No. } 19 \\
48-N o .22 \\
48-N o .22 \\
48-N o .22 \\
48-N o .19\end{array}$ & $\begin{array}{l}\text { 28-No. } 19 \\
\text { 28-No. } 22 \\
\text { 28-No. } 22 \\
\text { 28-No. } 22 \\
\text { 28-No. } 19\end{array}$ \\
\hline
\end{tabular}


Table 4. Steel coupling beam dimensions of the 10-story HCW example structures.

\begin{tabular}{|c|c|c|c|c|c|c|}
\hline \multirow[b]{2}{*}{$\mathrm{CR}$} & \multicolumn{4}{|c|}{ 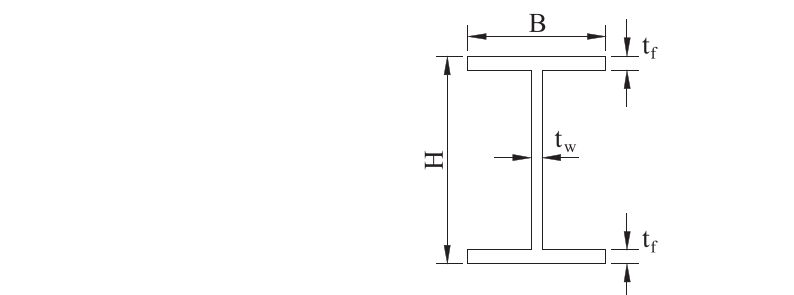 } & \multirow[b]{2}{*}{$t_{\mathrm{w}}(\mathrm{cm})$} & \multirow[b]{2}{*}{$\varphi V_{\mathrm{p}}(\mathrm{kN})$} \\
\hline & Level & $\mathrm{B}(\mathrm{cm})$ & $t_{\mathrm{f}}(\mathrm{cm})$ & $\mathrm{H}(\mathrm{cm})$ & & \\
\hline \multirow[t]{5}{*}{0.30} & 10 to roof & 30.00 & 3.00 & 30.60 & 0.80 & 366.64 \\
\hline & 8-9 & 30.00 & 3.00 & 40.60 & 0.80 & 515.68 \\
\hline & $6-7$ & 30.00 & 3.00 & 45.00 & 0.80 & 581.26 \\
\hline & $4-5$ & 30.00 & 3.00 & 45.00 & 0.90 & 653.91 \\
\hline & $2-3$ & 30.00 & 3.00 & 45.00 & 0.90 & 653.91 \\
\hline \multirow[t]{5}{*}{0.50} & 10 to roof & 35.00 & 3.00 & 46.00 & 0.80 & 596.16 \\
\hline & $8-9$ & 35.00 & 3.00 & 50.60 & 1.00 & 830.90 \\
\hline & $6-7$ & 40.00 & 3.00 & 54.60 & 1.10 & 995.96 \\
\hline & $4-5$ & 40.00 & 3.00 & 56.60 & 1.10 & 1036.95 \\
\hline & $2-3$ & 40.00 & 3.00 & 57.60 & 1.10 & 1057.44 \\
\hline \multirow[t]{5}{*}{0.75} & 10 to roof & 35.00 & 3.00 & 51.00 & 1.10 & 922.19 \\
\hline & 8-9 & 40.00 & 3.00 & 61.00 & 1.20 & 1229.58 \\
\hline & $6-7$ & 45.00 & 3.20 & 61.40 & 1.40 & 1434.51 \\
\hline & $4-5$ & 45.00 & 3.20 & 63.40 & 1.50 & 1592.87 \\
\hline & $2-3$ & 45.00 & 3.20 & 64.40 & 1.50 & 1620.81 \\
\hline
\end{tabular}

the second mode, the higher-mode demand $\left(Q_{2}\right)$ can be determined from elastic modal response analysis or by using the second mode pushover with the target displacement computed from the modal analysis.

The forces $Q_{\mathrm{y}}$ and $Q_{2}$ can be combined using the square root of the sum of squares approach to obtain the forces for design $\left(Q_{\text {Design }}\right)$.

Table 5. Steel coupling beam dimensions of the 20-story HCW structure.

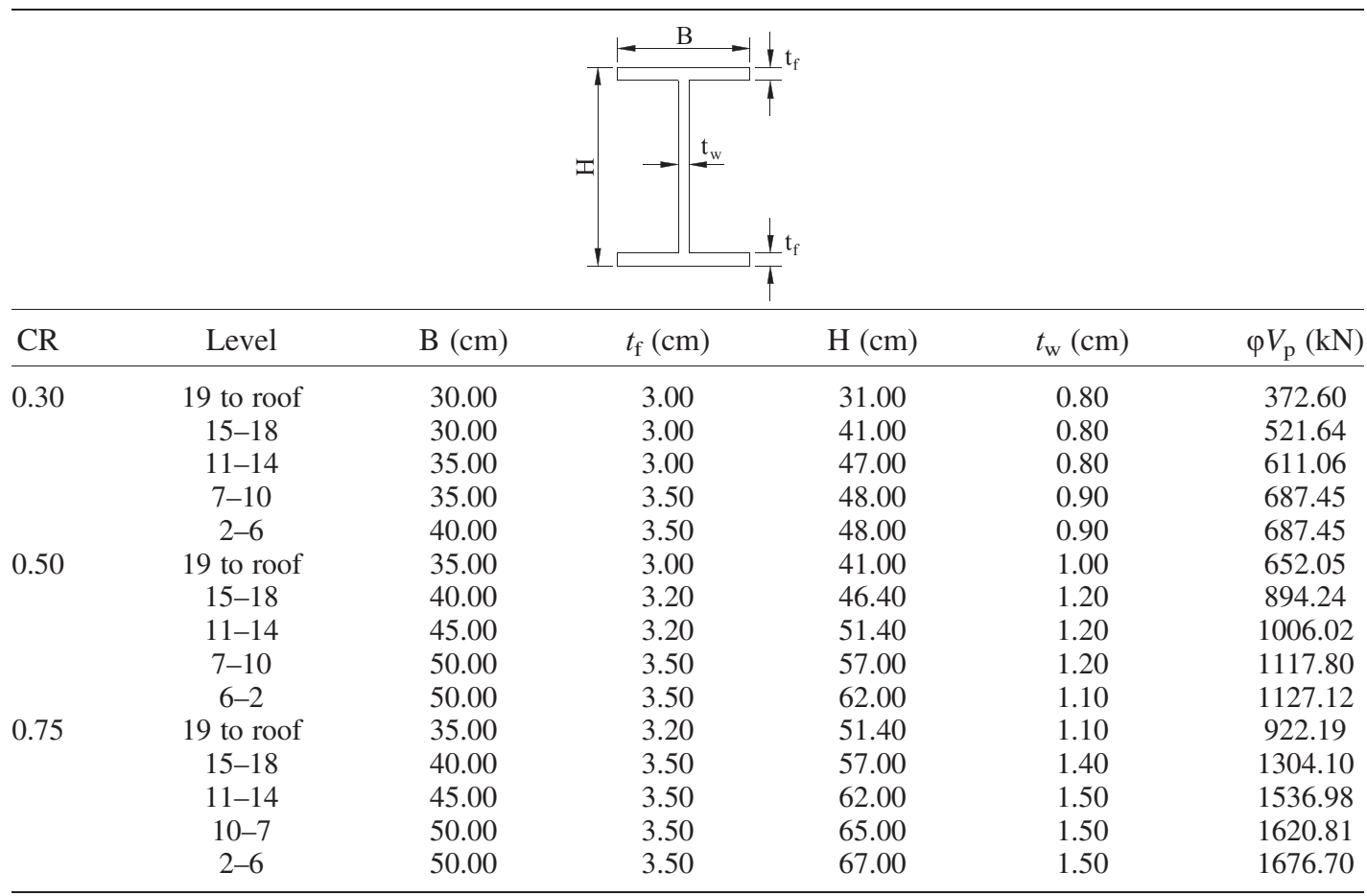



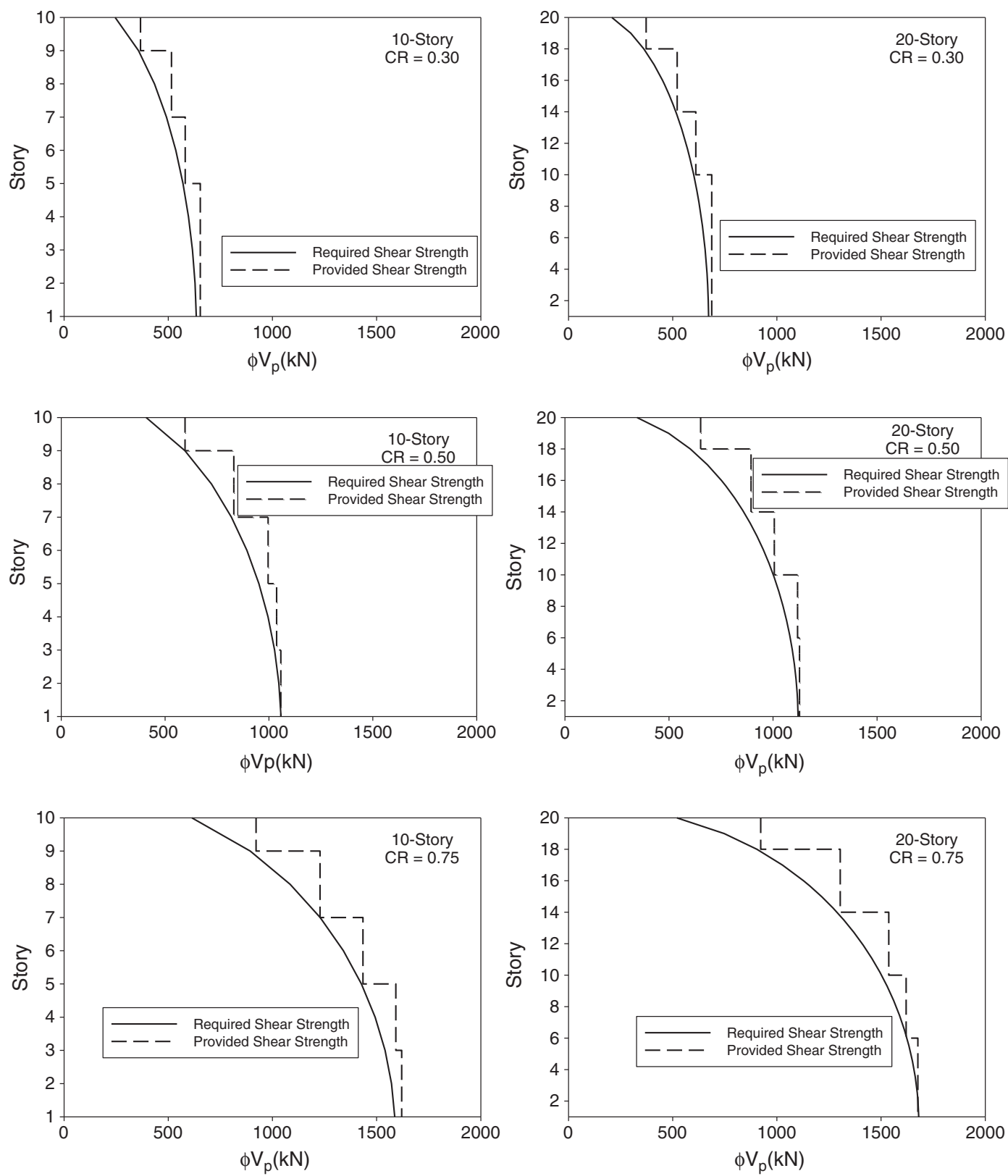

Figure 6. Required and provided shear strength of coupling beams.

$$
Q_{\text {Design }}=\sqrt{\left(\xi Q_{\mathrm{y}}\right)^{2}+Q_{2}^{2}}
$$

In Equation (12), $\xi$ is a factor that accounts for the material overstrength, strain-hardening, and the overstrength due to redistribution of internal forces during the development of the mechanism. The internal forces corresponding to the development of the base moment capacity, including overstrength $\left(\xi Q_{\mathrm{y}}\right)$, can be obtained directly from a pushover analysis of the system up to the design target drift. These forces can also be computed based on an equilibrium analysis of the mechanism shown in 

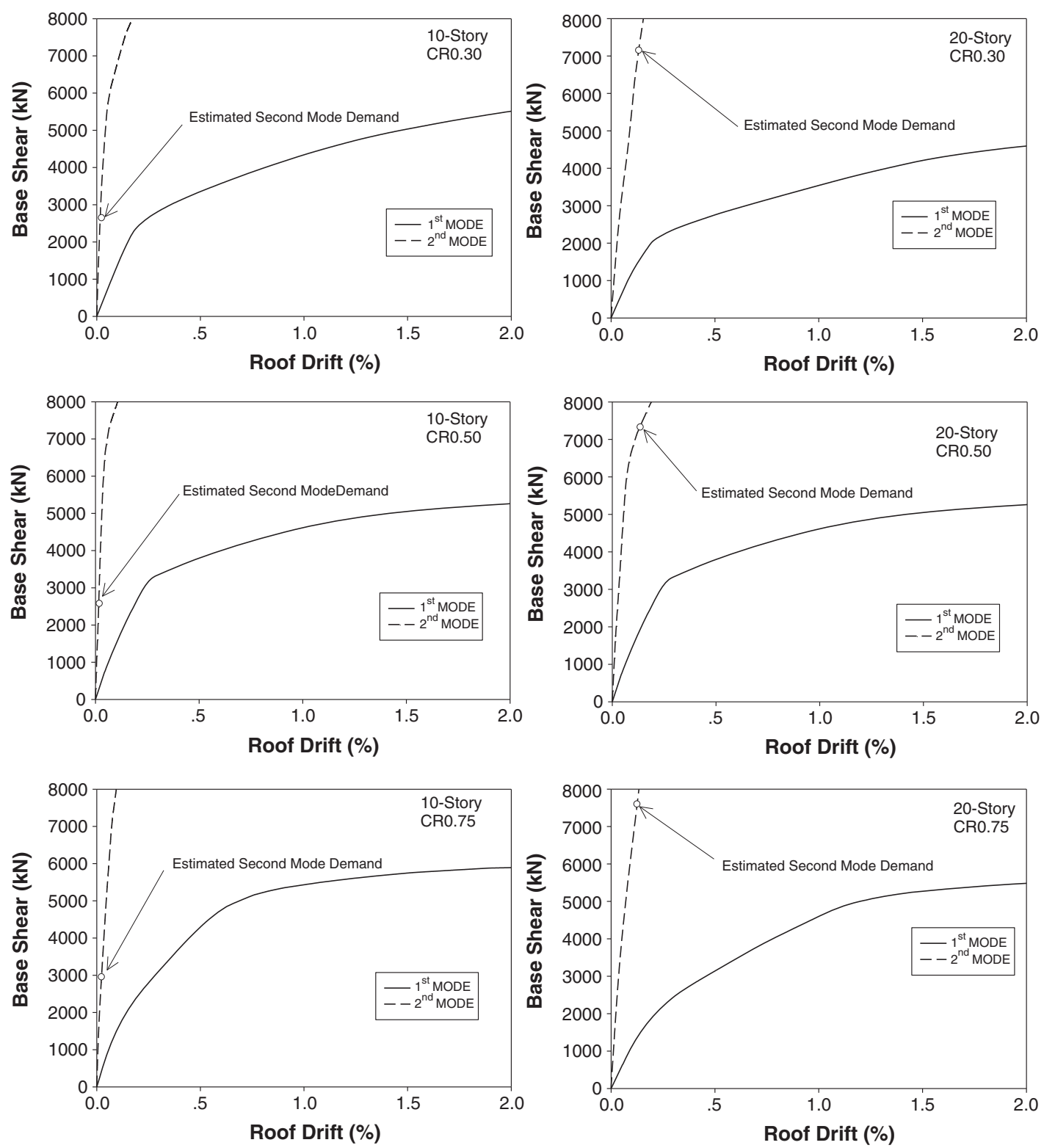

Figure 7. Pushover curves.

Table 6. Comparisons of base shear results from evaluation and the ones used in the design of the HCW structures.

\begin{tabular}{|c|c|c|c|c|c|c|}
\hline \multirow{2}{*}{ Design case } & \multirow{2}{*}{$\begin{array}{l}\text { Period } \\
\text { of the } \\
1 \text { st } \\
\text { mode } \\
(\mathrm{sec})\end{array}$} & \multirow{2}{*}{$\begin{array}{l}\text { Period } \\
\text { of the } \\
\text { 2nd } \\
\text { mode } \\
(\mathrm{sec})\end{array}$} & \multirow{2}{*}{$\begin{array}{l}\text { 2nd mode } \\
\text { Roof dis- } \\
\text { placement } \\
\text { demand } \\
(\mathrm{mm})\end{array}$} & \multicolumn{2}{|c|}{ Base shear from results of evaluation } & \multirow{2}{*}{$\begin{array}{c}\text { Base shear } \\
\text { used in design } \\
\begin{array}{c}V_{\text {Design }} \text { from } \\
\text { Equation }(12)(\mathrm{kN}\end{array}\end{array}$} \\
\hline & & & & $\begin{array}{l}\xi V_{\mathrm{y}} \text { at target } \\
\text { drift }(\mathrm{kN})\end{array}$ & $\begin{array}{l}\text { 2nd Mode demand; } \\
\qquad V_{2}(\mathrm{kN})\end{array}$ & \\
\hline 10-story CR 0.30 & 0.724 & 0.147 & 5.16 & 4127 & 2850 & 5320 \\
\hline 10-story CR 0.50 & 0.688 & 0.159 & 5.32 & 4440 & 2690 & 5486 \\
\hline 10-story CR 0.75 & 0.613 & 0.144 & 4.55 & 5354 & 2967 & 6653 \\
\hline 20-story CR 0.30 & 1.874 & 0.415 & 45.98 & 3876 & 7392 & 8378 \\
\hline 20-story CR 0.50 & 1.747 & 0.412 & 47.15 & 4421 & 7685 & 8811 \\
\hline 20-story CR 0.75 & 1.664 & 0.403 & 46.01 & 4553 & 7760 & 9210 \\
\hline
\end{tabular}




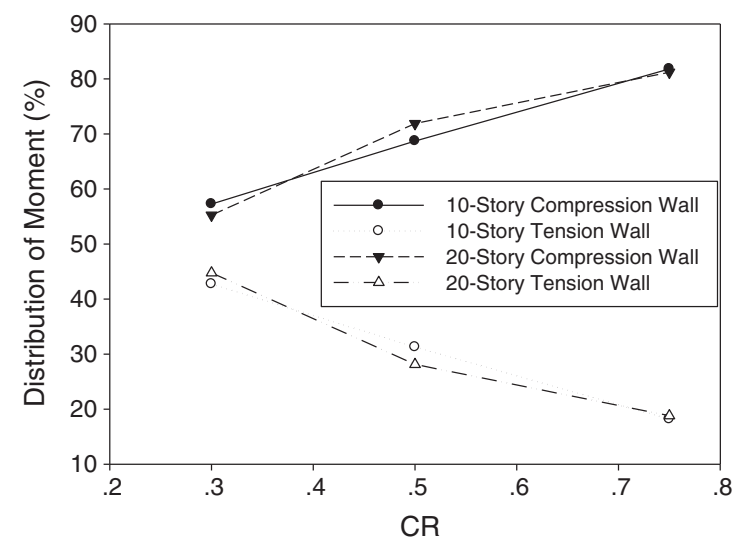

Figure 8. Distribution of moments at the bases of the walls.

Figure 1, with approximate overstrength factors applied to the forces induced by the coupling beams and the wall bases.

The use of $Q_{\mathrm{y}}$ forces to design the DYMs ensures that the performance of the structure stays within the prescribed level. At the same time, the inclusion of higher mode effects would ensure that the nonyielding members have adequate strength to remain elastic.

\section{EXAMPLE STRUCTURES}

In this study, prototype HCW structures of 10 and 20 stories (Figure 4) in height were selected and used to investigate the effectiveness of the PBPD method presented herein. The structure was similar to the one used by Chaallal and Ghlamallah (1996). The design was carried out for a seismic hazard level defined by spectral response acceleration parameters $S_{1}=0.8 \mathrm{~g}$ and $S_{\mathrm{s}}=1.2 \mathrm{~g}$, seismic use group $\mathrm{I}$, soil type $\mathrm{D}$, and estimated period values of 1.60 and $0.91 \mathrm{~s}$ for the 20 -story and 10-story structures, respectively. Three values of CR $(0.30,0.50$, and 0.75$)$ were used. The PBPD design parameters are summarized in Table 1. The target drifts were selected to limit the plastic rotations at the wall base to $0.4 \%$. The total moment strength of the walls at the bases required for each design case is shown in Figure 5. For the design of the wall sections at the bases, the required moment strengths were distributed to the wall on compression and tension sides in ratios of 60:40, 70:30, and 80:20 for CR values of $0.3,0.5$, and 0.75 , respectively. For design purposes, the wall sections above the bases were designed using the internal forces obtained from the pushover analysis of the system up to the design

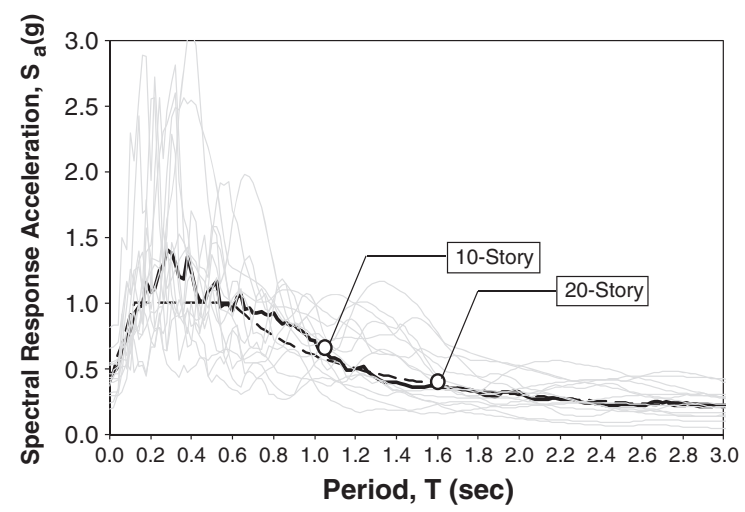

Figure 9. Spectra of the ground motions used in this study and the design spectrum. 

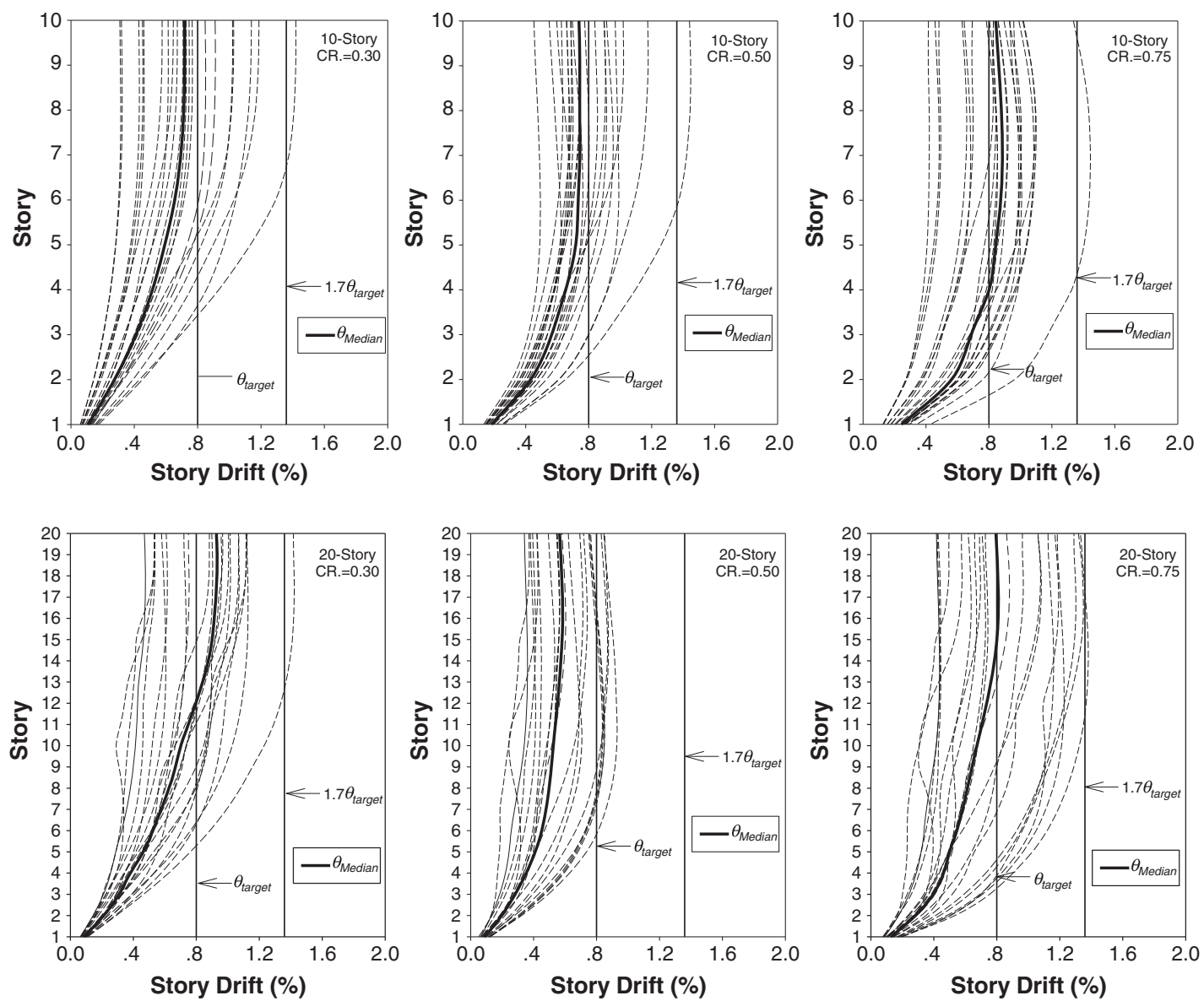

Figure 10. Story drifts from 20 ground motions.

target drift combined with the forces from the second mode based on elastic modal analysis according to Equation (12). The forces from the pushover analysis capture essentially the first mode response. The pushover was carried out by modeling the wall as elastic except at the bases where plastic hinges were allowed to form. This will allow the forces in the walls to develop according to the selected yield mechanism. These forces are then added to the forces from the second mode response.

The design of the reinforced concrete walls and the steel coupling beam were performed in accordance with ACI (2011) and AISC (2010), respectively. The design was carried out based on $f_{\mathrm{c}}{ }^{\prime}=35 \mathrm{Mpa}$ and $f_{\mathrm{y}}=420 \mathrm{Mpa}$. The final wall sections of the 10-story and 20-story structures are shown in Tables 2 and 3, respectively. The coupling beam sections are given in Tables 4 and 5. The required and provided shear strength of the coupling beams are shown in Figure 6.

\section{RESPONSE ANALYSIS}

The 10-story and 20-story example structures were subjected to the first and second mode pushover analyses as well as nonlinear response history analysis (NL-RHA) to study the response of the structures. For the computer models, lumped plasticity beam elements were assigned for the coupling beams. Fiber shell sections were used for the walls. Elastic gravity columns were also included in the model. Although trial analyses indicated that the gravity columns had very small effect on the response, they were included to capture the P-Delta effects. The analyses were carried out by Perform3D nonlinear analysis program (CSI 2007). 

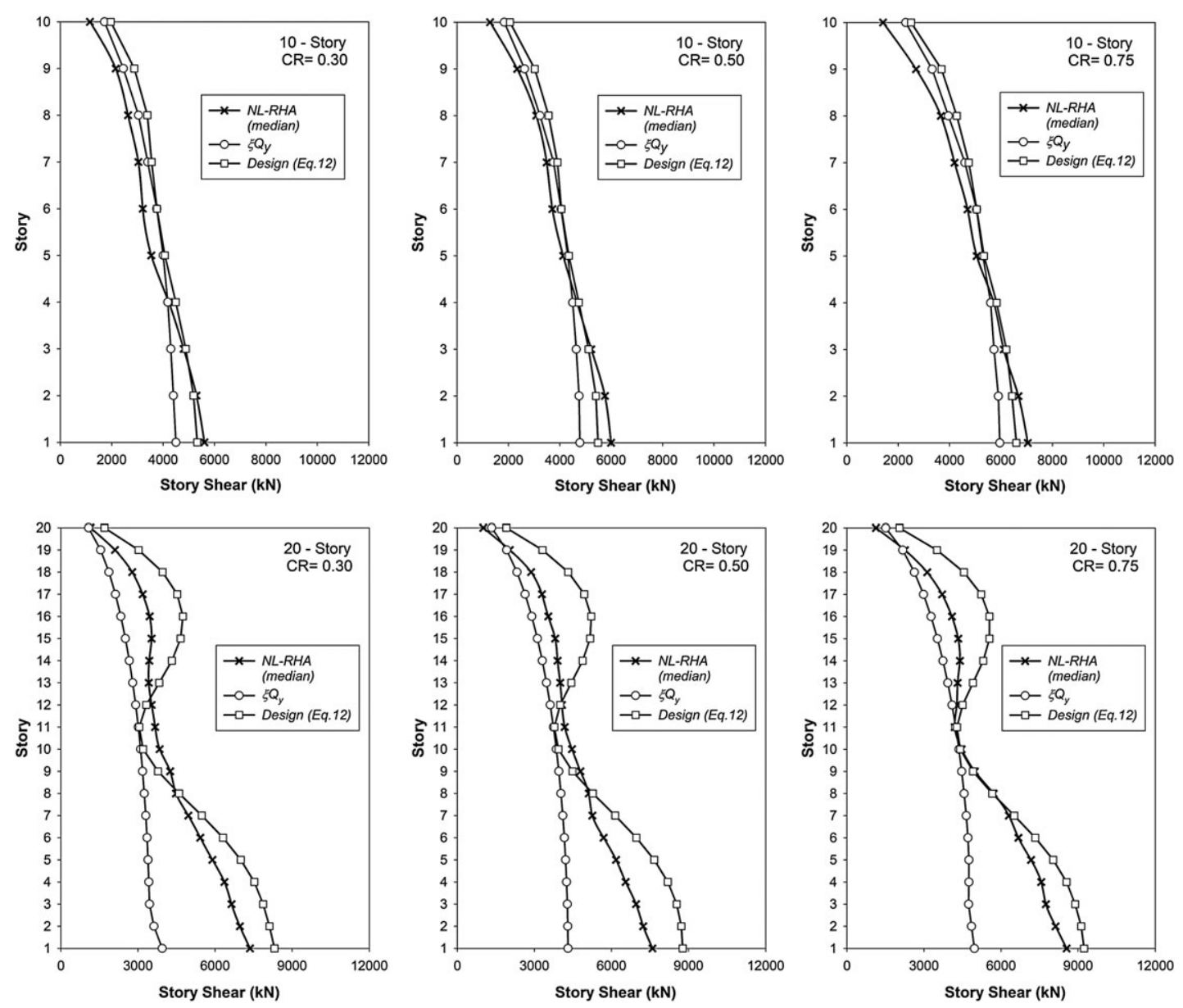

Figure 11. Comparison of story shear forces as a result of 20 ground motions with the design values.

The results from the first and second mode pushover analyses are shown in Figure 7. The second mode deformation demands were computed using the design spectrum created with the spectral acceleration parameters described earlier. The values of the base shears used in design, the base shears (including the overstrength) obtained from pushover evaluation at the design target drifts, and the base shears corresponding to the second mode deformation demands are given in Table 6 for comparison. It can be noticed from the pushover curves that the second mode response is nearly elastic as assumed in the design. In each case, the second mode response shows significantly larger stiffness. This implies that even a small deformation in the second mode can induce significant internal forces. The internal forces in the walls are the results of the forces induced by the beams framing the walls and the deformation of the walls as they continue to sway under the applied ground motions after the beams have already reached their plastic capacities. Because the stiffness of the walls is relatively large, the deformation due to the higher modes can induce significant internal forces. It is important to note that the higher mode effects and the overstrength of the walls must be taken into account in the design.

The distributions of the base moment for the walls on the compression and tension sides from the pushover evaluation are shown in Figure 8. The distributions show a strong correlation with the CR. The distribution depends on the stiffness and capacity of the wall sections, both of which are strongly influenced by the axial force in the walls. Because the axial force induced in the walls varies according to the $\mathrm{CR}$, the distribution of the wall strength should also be assigned based on the values of the coupling ratios. 

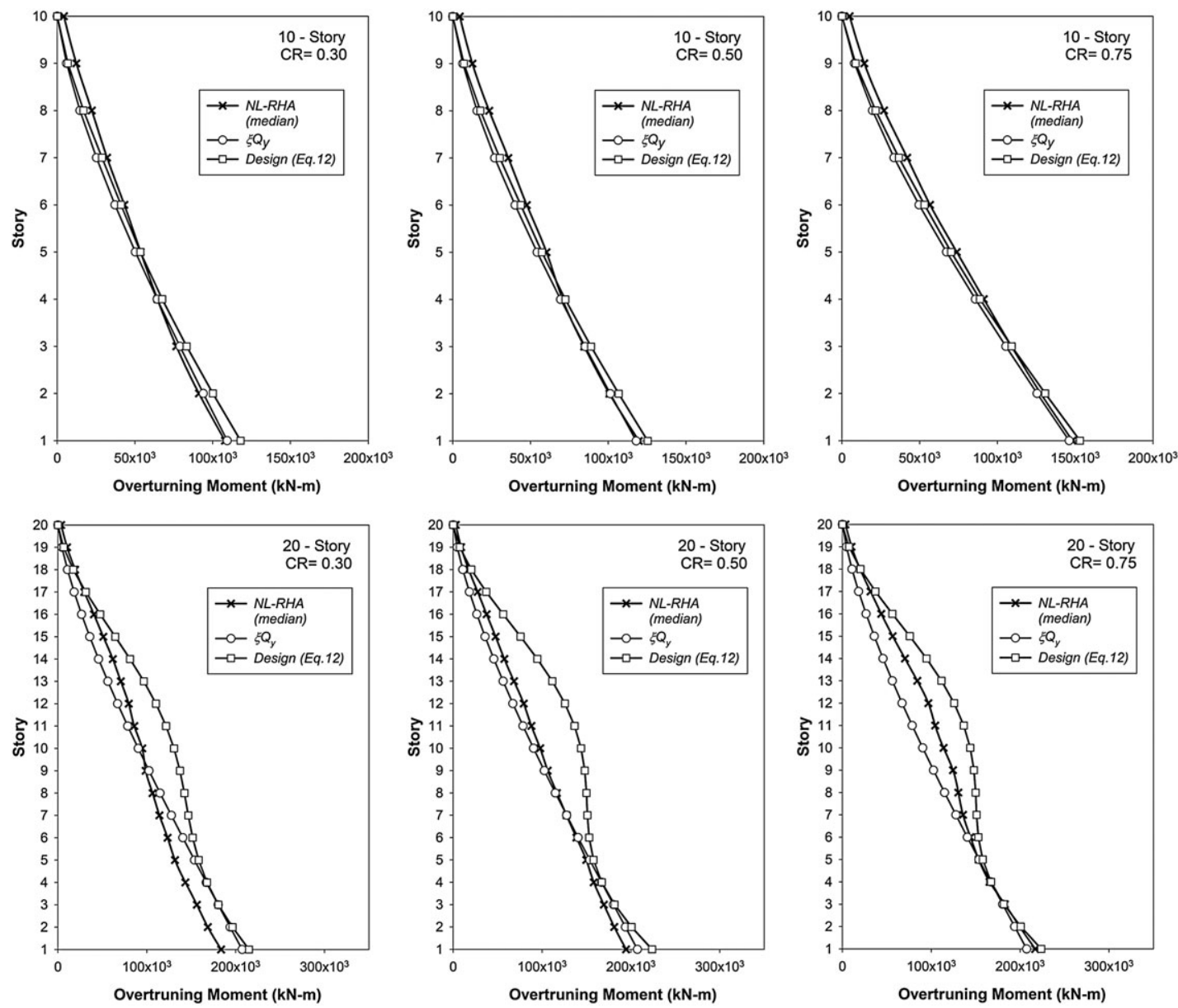

Figure 12. Comparison of overturning moment as a result of 20 ground motions with the design values.

For NL-RHA, the example structures were subjected to 20 ground motions. The 20 ground motions were taken from an existing study (Somerville et al., 1997). The ground motions were scaled such that their spectral acceleration values were approximately the same as those obtained from the design spectra at the fundamental periods. The spectra of the 20 ground motions for the 10-story and 20-story structures are shown and compared with their design spectra in Figure 9.

Maximum story drifts under the 20 ground motions from NL-RHA, and their median values are compared with the target and the expected maximum drift $\left(\theta_{\text {target }}\right.$ and $\left.\theta_{\max }=1.7 \theta_{\text {target }}\right)$ as shown in Figure 10. In general, for the lower stories, the story drifts are small and are less than the target values. The coupling ratios had a large effect on the story drifts, particularly in the upper stories. The story drifts in the upper stories are significantly larger than the story drifts in the middle and lower stories for the CR value of 0.3 . In both the 10-story and 20-story structures, CR value of 0.5 appears to be suitable, and there seems to be no additional benefit in using CR beyond 0.5. The drift values were all kept near the target values. The variation in the story drifts may be reduced by using a load distribution developed especially for coupled wall structures (Chao et al., 2007). However, this is beyond the scope of the present study.

The distributions of story shears for the example structures are shown in Figure 11. The median values of the maximum story shears under 20 ground motions are provided and compared with the PBPD story shear forces prior to the combination with the second mode. For the 20-story structure, the story shears from NL-RHA are significantly larger than the story shears given by Equation (4) due to the deformation of the walls after the coupling beams have already yielded as discussed earlier. When the forces from the deformation due to the second mode and the overstrength are included, the 

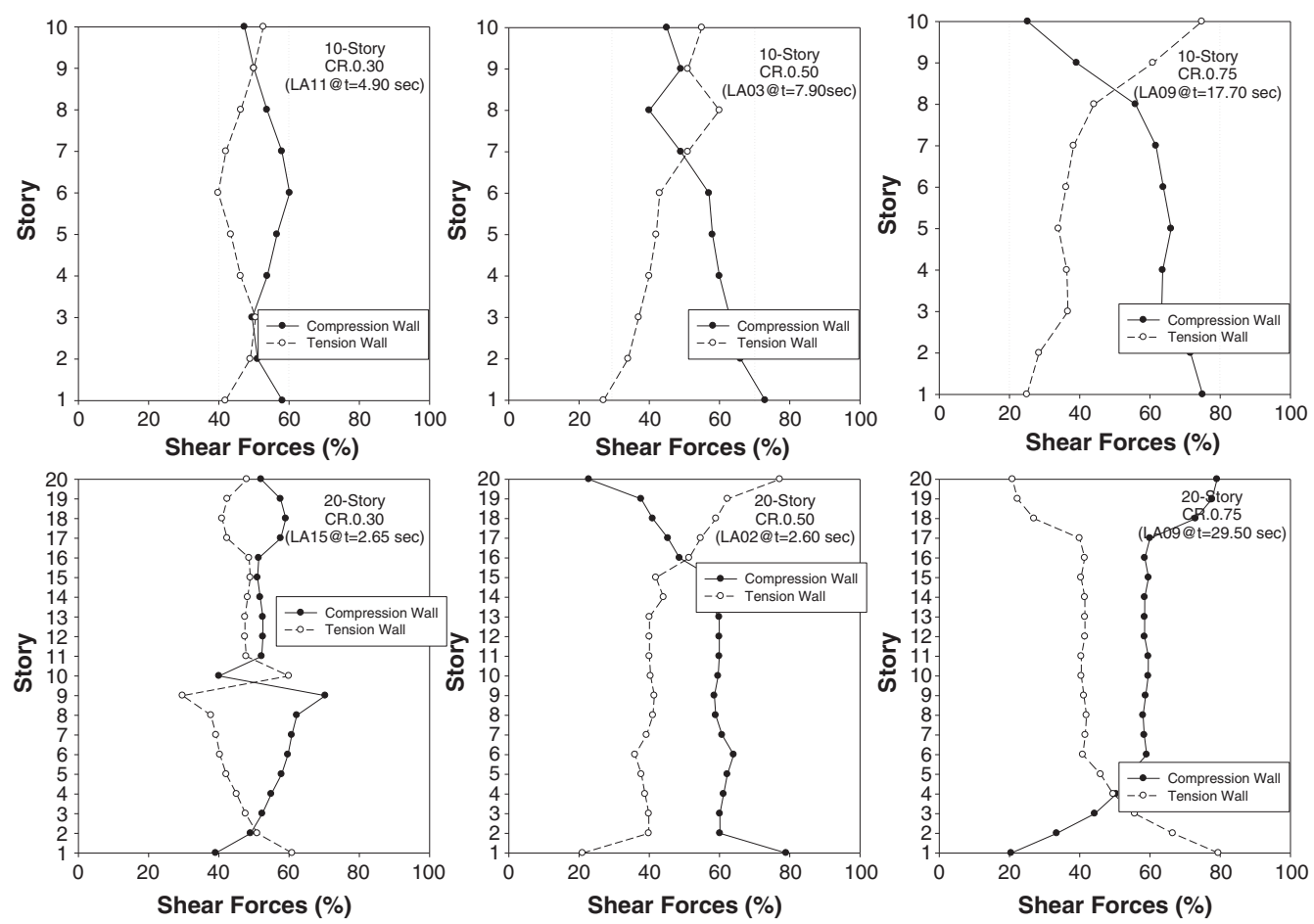

Figure 13. Distribution of shear forces (\%).

forces computed using Equation (12) provided reasonable estimates of the maximum story shears. At the base of the structures, the ratios of the median maximum base shear from the NL-RHA divided by the base shears given by Equation (4) (without the second mode demand and overstrength) are
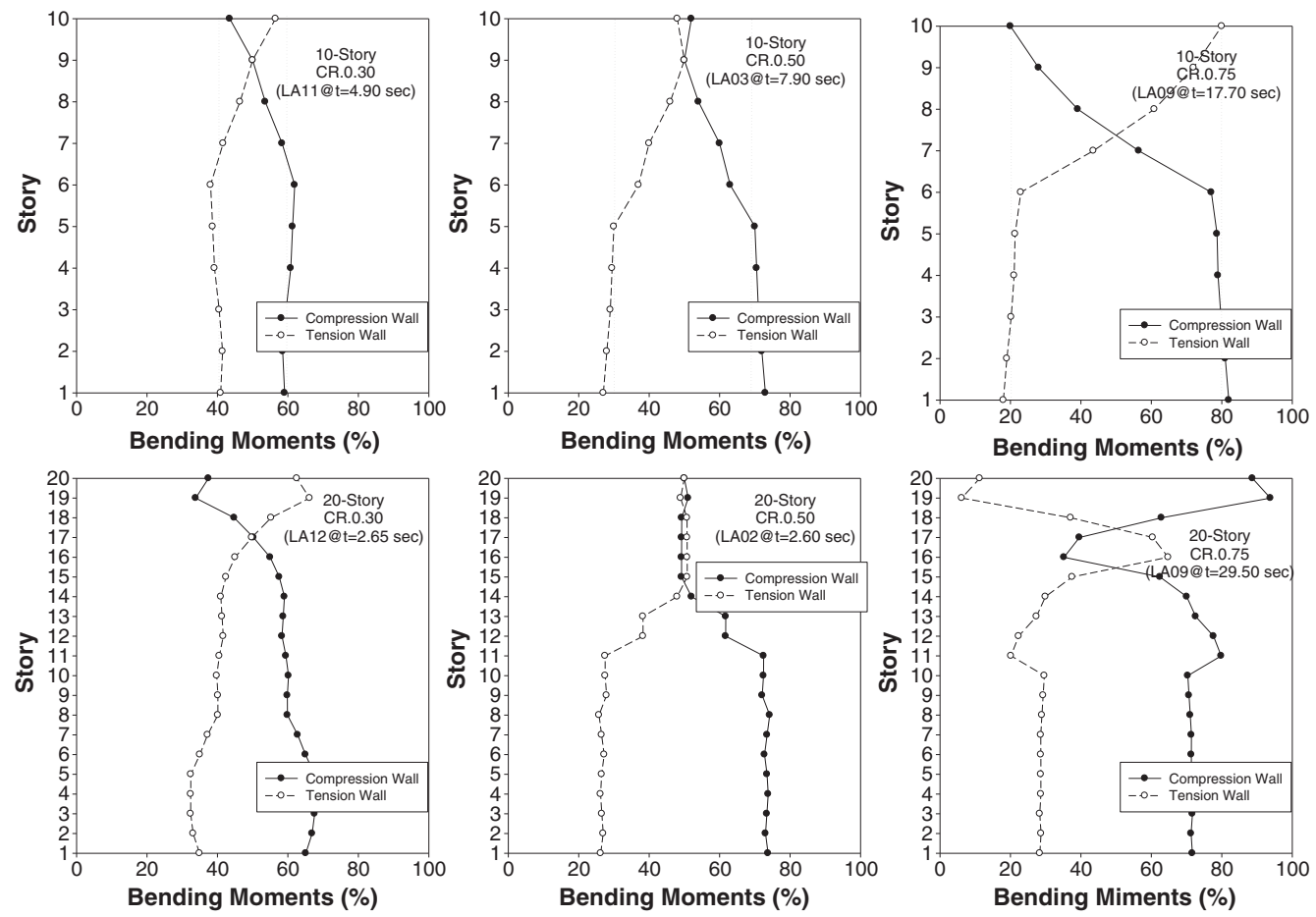

Figure 14. Distribution of bending moments (\%). 
generally larger than two and can be as high as three. The ratio appears to increase as the CR becomes larger. The overturning moments for the example structures are shown in Figure 12. The wall bending moment shows less influence of the higher modes as compared with the case of story shear. Nevertheless, compared with the PBPD design overturning moment determined without second mode contribution, the moments from the nonlinear dynamic analysis are still significantly larger for the case of the 20 -story structure with high CR values.

The distribution of shear forces and bending moments in compression and tension walls at times of peak roof drifts under selected ground motions are shown in Figures 13 and 14. The results from these ground motions were chosen because they produced story drifts closed to median drift values. The distribution shows a strong correlation with CR similar to the results from the pushover analysis. As the $\mathrm{CR}$ becomes larger, the wall on the compression side carries a significantly larger portion of the overall moment and shear force. The suggested distribution for design of 60-40, 70-30, and 80-20 for CR of $0.3,0.5$, and 0.75 are also indicated in the figure.

\section{CONCLUSIONS}

In this paper, an improved design method for HCW systems based on a design procedure called the PBPD method is presented. Hybrid coupled wall structures with varying heights and coupling ratios were designed and subjected to a series of nonlinear time history analyses. The key response parameters, including important aspects of the higher mode effects, are presented and discussed. The main findings and design implication can be summarized as follows.

- The PBPD is an effective performance-based design method for HCW systems. The method achieved the intended performance objectives even when no design iterations were involved.

- The coupling ratio has a large effect on controlling the story drifts, particularly in the upper stories. A CR value of 0.5 is recommended for HCW systems when plastic design is utilized. Because actual wall structures vary in size, heights, and complexity, more rigorous analyses such as nonlinear time history that consider multiple seismic hazard scenarios should be consider for a final design check.

- Higher mode effects can significantly affect the internal forces of the non-yielding elements (the walls in this case). The results indicated that under seismic excitations, the internal forces could be significantly larger than the forces based on the first mode distribution alone. This is primarily due to high stiffness and response in the higher modes as well as overstrength of the system. The design must take these effects into account to achieve the selected yield mechanism. This could be carried out by the proposed method, which can be readily incorporated into the PBPD framework.

- For the design of the walls, the distribution of wall moments on the tension and compression sides of the walls depends strongly on the CR. For low CR values, the walls behave as isolated walls, and the two walls carry approximately equal bending moment. As the CR becomes larger, the wall on the compression side carries a significantly larger portion of the overall moment due to higher axial force on the wall. Analyses carried out in this study indicated that the distribution is on the order of 60-40 for a CR of 0.3 . This distribution changes progressively to approximately 70-30 for a CR of 0.5 and 80-20 for a CR of 0.7. These values are suggested for design purposes.

\section{REFERENCES}

ACI. 2011. Building code requirements for structural concrete (ACI 318-11) and commentary. (ACI 318R-11). American Concrete Institute, Farmington Hills, MI.

AISC. 2010. ANSI/AISC 360-10, Specification for Structural Steel Buildings. Chicago, IL: American Institute of Steel Construction.

ASCE. 2005. Minimum Design Loads for Buildings and Other Structures. (ASCE 7-05) American Society of Civil Engineers: Reston, VA.

Beyer K, Priestley MJN, Calvi GM, Pinho R. 2005. Design and analysis of walls coupled by floor diaphragms. A dissertation Submitted in Partial for the Master Degree in Earthquake Engineering, Rose School, Pavia PV.

Chaallal O, Ghlamallah N. 1996. Seismic response of flexibly supported coupled shear walls. ASCE Journal of the Structural Engineering 122(10): 1187-1197. 
Chan-Anan W, Leelataviwat S, Goel SC. 2010. Plastic design of hybrid coupled walls considering higher mode effects. The third ASIA Conference on Earthquake Engineering (ACEE 2010), Bangkok, Thailand, 1-3 December.

Chan-Anan W, Leelataviwat S. 2015. Performance-based plastic design method for single and coupled shear walls structures. International Conference on Civil Engineering and Environmental Engineering (ICCEE 2015), Tokyo, Japan, 3-5 February.

Chao S-H, Goel SC. 2006. Performance-based seismic design of special truss moment frames. Proceeding of the fourth International Conference on Earthquake Engineering, Taiwan.

Chao S-H, Goel SC, Lee S-S. 2007. A seismic design lateral force distribution based on inelastic state of structures. Earthquake Spectra 23(3): 547-569.

Chao S-H, Bayat MR, Goel SC. 2008. Performance-based seismic design of steel concentric braced frames for enhanced confidence level. Proceeding of the $14^{\text {th }}$ World Conference on Earthquake Engineering, China.

CEN, Comité Européen de Normalisation. 2004. Eurocode 8, Design of Structures for Earthquake Resistance - Part1: General Rules, Seismic Actions and Rules for Buildings. Brussels, Belgium: British Standard.

CSI. 2007. Perform-3D Nonlinear Version 4.0 User Manual. Computer \& Structures Inc.: Berkeley, CA.

Eibl J, Keintzel F. 1988. Seismic shear forces in RC cantilever shear walls. Proceeding of The Ninth World Conference on Earthquake Engineering: Tokyo/Kyoto, Japan.

El-Tawil S, Harries KA, Fortney PJ, Shahrooz BM, Kurama Y. 2010. Seismic design of hybrid coupled wall systems: state of the Art. ASCE Journal of Structural Engineering 136(7): 755-769.

Fox MJ, Sullivan TJ, Beyer K. 2014. A case study in the capacity design of RC coupled walls. Proceedings of the Second European Conference on Earthquake Engineering and Seismology: Istanbul.

Goel SC, Chao S-H. 2008. Performance-based Plastic Design: Earthquake Resistant Steel Structures. International Code Council: Washington, DC.

Goel SC, Liao WC, Bayat MR, Chao S-H. 2010. Performance-based plastic design (PBPD) method for earthquake-resistant structures: an overview. Journal of The structural Design of Tall and Special Buildings 19: 115-137.

Harries KA, Mitchell D, Cook WD, Rewood RG. 1993. Seismic response of steel beams coupling concrete walls. ASCE Journal of Structural Engineering 119(12): 3611-3629.

Hassan M, El-Tawil S. 2004. Inelastic dynamic behaviour of hybrid coupled walls. ASCE Journal of Structural Engineering 130 (2): $285-296$.

Hassan M, El-Tawil S. 2006. Comparison between seismic behavior of 12-and 18-story hybrid coupled wall systems. The Fifth of Composite Construction in Steel and Concrete: 664-673.

Leelataviwat S, Saewon W, Goel SC. 2008. Application of energy balance concept in seismic evaluation of structures. ASCE Journal of Structural Engineering 135(2): 113-121.

Lee S-S, Goel SC. 2001. Performance-based design of steel moment frames using target drift and yield mechanism. Research Report No. UMCE 01-17. Department of Civil and Environmental Engineering, University of Michigan, Ann Arbor, MI

NEHRP. 2009. Recommended seismic provisions for new buildings and other structures: part 3, resource papers (RP) on special topics in seismic design. Resource Paper 9, National Earthquake Hazards Reduction Program, Seismic Safety Council, National Institute of Building Sciences. Washington, D.C.

Newmark NM, Hall WJ. 1982. 'Earthquake spectra and design,' Engineering Monographs on Earthquake Criteria, Structural Design, and Strong Motion Records, Vol. 3, Earthquake Engineering Research Institute, Berkeley, CA.

Park W-S, Yun H-D. 2005. Seismic behaviour of coupling beams in a hybrid coupled shear walls. Elsevier Journal of Constructional Steel 61: 1492-1524.

Priestley MJN, Calvi GM, Kowalsky MJ. 2007. Displacement-based Seismic Design of Structures. IUSS PRESS: Pavia, Italy. Somerville PG, Smith M, Punyamurthual S, Sun J. 1997. Development of ground motion time histories for phase 2 of the FEMA/SAC steel project. Report No. SAC/BD-97/04, SAC Joint Venture, Sacramento, CA.

\section{AUTHORS' BIOGRAPHIES}

Watchara Chan-Anan is a Lecturer at the Department of Civil Engineering, Nakhon Pathom Rajabhat University, Thailand. He graduated with his B.E. from Southeast Asia University in 2003 and ME from King Mongkut's University of Technology North Bangkok in 2006. He is currently a $\mathrm{PhD}$ candidate at the King Mongkut's University of Technology Thonburi. His current research involves seismic design of hybrid RC-Steel structures.

Sutat Leelataviwat is currently an Associate Professor at King Mongkut's University of Technology Thonburi, Bangkok, Thailand. He graduated with his BE, from Chulalongkorn University, Thailand, in 1993, and obtained his MS and $\mathrm{PhD}$ degrees in the field of structural engineering from the University of Michigan, Ann Arbor, USA, in 1995 and 1999, respectively. After receiving his PhD, he worked as a Structural Engineer in the USA and in Thailand prior to joining King Mongkut's University of Technology Thonburi in 2004. He has been involved in many related research and consultancy 
projects. His research interests include seismic design of steel structures, seismic retrofitting of nonductile RC frames, and energy-based plastic design of structures.

Subhash C. Goel is currently an Emeritus Professor at the University of Michigan at Ann Arbor. He received his B in 1958, ME in 1961 from the University of Roorkee, India, and PhD from the University of Michigan in 1968. His research activities have involved analytical and experimental studies of seismic behavior of steel and composite Steel-RC or masonry structures with the objectives to develop rational analytical models for use in analysis and design, as well as to formulate improved methods for earthquake-resistant design of safer and more economical structures for new construction as well as upgrading of existing structures. He has also received numerous awards including the 1997 T.R Higgins Lectureship Award from the American Institute of Steel Construction, the 1999 NOVA Award from Construction Innovation Forum for the development of the Special Truss Moment Framing System for seismic resistance, and the 2004 Shortridge Hardesty Award from the American Society of Civil Engineers. 